\title{
Prevalence and distribution of livestock schistosomiasis and fascioliasis in Côte d'Ivoire: results from a cross-sectional \\ survey
}

Jules N. Kouadio ${ }^{1,2,3,4^{*}}$ (D), Jennifer Giovanoli Evack ${ }^{3,4}$, Louise Y. Achi ${ }^{2,5}$, Dominik Fritsche ${ }^{6}$, Mamadou Ouattara ${ }^{1,2}$, Kigbafori D. Silué ${ }^{1,2}$, Bassirou Bonfoh², Jan Hattendorf ${ }^{3,4}$, Jürg Utzinger ${ }^{3,4}$, Jakob Zinsstag ${ }^{3,4}$, Oliver Balmer ${ }^{3,4}$ and Eliézer K. N'Goran ${ }^{1,2}$

\begin{abstract}
Background: Schistosoma and Fasciola are zoonotic parasites of public health and veterinary importance. However, while the epidemiology of schistosomiasis in humans is well studied, little is known about fascioliasis and schistosomiasis in livestock in Côte d'Ivoire. This study aimed to determine the prevalence and the distribution of livestock schistosomiasis and fascioliasis across Côte d'Ivoire.

In 2018, we conducted a cross-sectional survey in abattoirs and farms in 13 departments of Côte d'Ivoire. In abattoirs, the mesenteric veins and livers of slaughtered cattle, sheep and goats were examined for adult Schistosoma and Fasciola flukes. Faeces from live cattle, goats and sheep were collected and examined for Schistosoma and Fasciola eggs using a sedimentation technique.

Results: A total of 386 cattle, 174 goats and 151 sheep from abattoirs and 435 cattle, 22 goats and 176 sheep from farms were sampled. The observed prevalence of schistosomiasis was higher in slaughtered animals. Fascioliasis was more prevalent in farm animals. The prevalence of schistosomiasis in slaughtered cattle varied between 5.9\% (95\% confidence interval (Cl): 0.7-19.7\%) and 53.3\% (95\% Cl: 37.9-68.3\%) with the highest prevalence observed in Ouangolodougou in the North. Cattle from farms had a relatively low prevalence of schistosomiasis, with the highest prevalence found in Ouangolodougou (2.4\%, 95\% Cl: 0.7-6.1\%). The prevalence of fascioliasis varied considerably from one department to another, ranging from nil (95\% Cl: 0.0-18.5\%) to 50.8\% (95\% Cl: 43.4-58.2\%), with the highest prevalence found in farm cattle in Dikodougou in the North. Sheep and goats had a lower prevalence of schistosomiasis and fascioliasis than cattle. In slaughtered animals, cattle aged 4 years and older were at highest risk for schistosomiasis (odds ratio (OR): 2.4; 95\% Cl: 1.0-5.6) and fascioliasis (OR: 2.1; 95\% Cl: 1.1-3.9). In farm animals, male cattle had higher odds of being infected with Schistosoma (OR: 4.3; 95\% Cl: 0.7-26.9) than females.

(Continued on next page)
\end{abstract}

\footnotetext{
* Correspondence: jules.kouadio@csrs.ci

'Unité de Formation et de Recherche Biosciences, Université Félix Houphouët-Boigny, 22 BP 770 Abidjan 22, Abidjan, Côte d'Ivoire

${ }^{2}$ Centre Suisse de Recherches Scientifiques en Côte d'Ivoire, 01 BP 1303 Abidjan 01, Abidjan, Côte d'Ivoire

Full list of author information is available at the end of the article
}

C C The Author(s). 2020 Open Access This article is licensed under a Creative Commons Attribution 4.0 International License, which permits use, sharing, adaptation, distribution and reproduction in any medium or format, as long as you give appropriate credit to the original author(s) and the source, provide a link to the Creative Commons licence, and indicate if changes were made. The images or other third party material in this article are included in the article's Creative Commons licence, unless indicated otherwise in a credit line to the material. If material is not included in the article's Creative Commons licence and your intended use is not permitted by statutory regulation or exceeds the permitted use, you will need to obtain permission directly from the copyright holder. To view a copy of this licence, visit http://creativecommons.org/licenses/by/4.0/ The Creative Commons Public Domain Dedication waiver (http://creativecommons.org/publicdomain/zero/1.0/) applies to the data made available in this article, unless otherwise stated in a credit line to the data. 
(Continued from previous page)

Conclusions: Our study confirms that schistosomiasis and fascioliasis are endemic in livestock across Côte d'Ivoire. A strategic control programme should be considered, especially for cattle, including providing drinking water in troughs to reduce faecal contamination of water sources by cattle.

Keywords: Côte d'Ivoire, Cross-sectional survey, Epidemiology, Fasciola, Livestock, Schistosoma

\section{Background}

Schistosomiasis and fascioliasis are zoonotic diseases with a complex transmission cycle involving aquatic snails as intermediate hosts and mammalian definitive hosts $[1,2]$. Schistosomiasis and fascioliasis are both caused by trematodes; the former by the genus Schistosoma, the latter by the genus Fasciola [3, 4]. Schistosomiasis and fascioliasis are widespread in tropical and subtropical regions of the world where climatic, ecological and hygienic conditions favour their transmission $[3,5]$. Besides their considerable public health burden [6], schistosomiasis and fascioliasis are responsible for economic loss in livestock, mainly through reduced fertility and productivity, liver condemnation, stunted growth and premature death [7-9].

Schistosomiasis also exists in wild and domestic animals and a wide range of mammals are susceptible to schistosome infection, including buffaloes, camels, cattle, goats, horses, pigs and sheep [10-12]. Schistosoma species that affect mammals include Schistosoma bovis, S. curassoni, S. hippopotami, S. indicum, S. intercalatum, S. mattheei, $S$. nasalis, S. rohhaini and S. spindale [13]. In many countries, $S$. bovis is one of the main species of veterinary and zoonotic importance $[8,14,15]$. In West Africa, $S$. bovis and S. curassoni are responsible for schistosomiasis in cattle and small ruminants (goat and sheep), respectively $[16,17]$. The prevalence of bovine schistosomiasis varies greatly from $1.2 \%$ in Nigeria [18] to $21.7 \%$ in Ghana [19]. In Côte d'Ivoire, human schistosomiasis has been the subject of numerous epidemiological studies [20-22]. In contrast, livestock schistosomiasis, has received little attention [23], despite the economic importance of livestock in the country. Prevalence of livestock schistosomiasis has been reported at $35 \%$ in the northern part of the country [23]. Of note, recent studies have found that S. bovis is involved in the hybridisation of schistosomes in humans in Côte d'Ivoire [24, 25].

Fascioliasis is a chronic disease with a global distribution that mainly occurs in domestic ruminants [26, 27]. There are two Fasciola species; namely Fasciola hepatica and F. gigantica. The former is a cosmopolitan species adapted to temperate areas, while F. gigantica is responsible for fascioliasis in tropical and subtropical regions of Africa and Asia [28-30]. In areas where both species coexist, F. hepatica x F. gigantica hybrids have been found [31-33]. Recently, the presence of hybrids has also been confirmed in sub-Saharan Africa [34]. Fascioliasis is endemic in West Africa with the predominant species being F. gigantica $[35,36]$. The disease has been reported in cattle with prevalence rates of $6.4-24.8 \%$ in Benin [37], 51.1\% in Ghana [19], 7-50\% in Mali [38] and $28-75 \%$ in Nigeria [18, 39-42]. Fascioliasis was also noted in North Côte d'Ivoire in 2003, with a prevalence of $F$. gigantica in cattle of $4 \%$ [23], however very little knowledge on the disease situation has been gained since then. Liver condemnation due to fascioliasis is frequent in abattoirs across the country.

The purpose of this study was to provide an overview of the epidemiology of schistosomiasis and fascioliasis in livestock by investigating the prevalence and the distribution of these diseases across Côte d'Ivoire. We designed a cross-sectional survey in abattoirs to collect adult flukes from slaughtered animals and surveyed animals on farms to identify parasite eggs in their faeces.

\section{Results}

\section{Characteristics of the animal populations}

A total of 711 slaughtered animals (386 cattle, 174 goats and 151 sheep) from abattoirs and 933 farm animals (735 cattle, 22 goats and 176 sheep) were sampled. Most animals were females, consisting of at least $61.4 \%$ in each group. Cattle breeds included "Taurin”, "Zébu” and "Taurin x Zébu". "Zébu" were the most commonly slaughtered cattle (42.5\%), while "Taurin x Zébu" were the most common breed found on the farms (79.9\% of live cattle). Most of the cattle (79.6\%) were at least 4 years old, both on farms and in abattoirs. As in cattle, more than $60 \%$ of the goats and sheep sampled were females on farms and in abattoirs. Goat breeds consisted of "Naine" and "Sahelien". The local breed "Naine" was the most common, at $98.9 \%$ and $100 \%$ of slaughtered and live goats, respectively. Sheep breeds included "Djallonké", "Sahelien" and "Djallonké x Sahelien". As with goats, the local breed "Djallonké" was the most common breed at $98.7 \%$ and $89.2 \%$ in abattoirs and on farms, respectively.

\section{Prevalence of Schistosoma and Fasciola Prevalence of Schistosoma and Fasciola infections in slaughtered animals}

Post-mortem examination of livers and small intestines in slaughterhouses revealed the presence of Schistosoma 
spp. and F. gigantica in $12.8 \%$ and $11.3 \%$, respectively, of all slaughtered animals (cattle, goats and sheep). The mean prevalence of Schistosoma and Fasciola flukes in cattle across all departments was $22.5 \%$ and $19.7 \%$, respectively (Table 1). Goats and sheep were considerably less often infected than cattle (Table 1). In goats, no Fasciola flukes were found, whereas Schistosoma flukes were found in $1.2 \%$ of the animals (Table 1). In sheep, Schistosoma and Fasciola flukes were found at a prevalence of $1.3 \%$ and $2.7 \%$, respectively (Table 1 ). The highest prevalence of S. bovis and F. gigantica were found in slaughtered cattle, $53.3 \%$ and $40.6 \%$, respectively.

The association between parasitic infection and sex, age and breed of slaughtered cattle are summarised in Table 2. Cattle aged 4 years and older showed the highest odds of $S$. bovis infection (multiple OR: 2.4; 95\% CI: 1.0-5.6). There was no significant association with sex (multiple OR: 1.1; 95\% CI: 0.6-1.8). The breeds "Taurin" (multiple OR: 0.9; 95\% CI: 0.3-2.8) and "Zébu" (multiple OR: 0.6 ; 95\% CI: $0.2-1.8$ ) had lower odds of infection than "Taurin x Zébu".

In regards to fascioliasis, cattle aged 4 years and older had the highest odds of infection (multiple OR: 2.1; 95\% CI: 1.1-3.9). Sex showed no association with fascioliasis (1.0; 95\% CI: 0.6-1.6). The breeds "Taurin" (multiple OR: 0.4; 95\% CI: 0.2-0.9) and "Zébu" (multiple OR: 0.7; 95\% CI: 0.5-1.1) had lower odds of infection compared to "Taurin x Zébu".

\section{Prevalence of Schistosoma and Fasciola infections in farm animals}

Farm animals were found infected with Schistosoma spp. and F. gigantica, as determined by parasite eggs in faecal samples. In cattle, the overall prevalence of $S$. bovis and F. gigantica was $0.7 \%$ and $29.5 \%$, respectively (Table 3 ). The prevalence of Schistosoma spp. was higher in goats than in sheep, while the contrary was observed for $F$. gigantica; but no significant difference was observed. The highest prevalence of Schistosoma (13.6\%) and Fasciola (50.8\%) were found in goats and cattle, respectively.

The association between parasitic infections and sex, age and breed of farm cattle are shown in Table 4. Males had higher odds of being infected with $S$. bovis (multiple OR: 4.3; 95\% CI: 0.7-26.9). Cattle aged 4 years and older had lower odds of Schistosoma infection compared to cattle younger than 4 years (multiple OR: 0.6; 95\% CI: 0.2-2.3), but these associations lacked statistical significance.

For fascioliasis, sex showed no strong association (multiple OR: 1.1; 95\% CI: 0.8-1.7). Cattle aged 4 years and older had higher odds of infection compared to their younger counterparts (multiple OR: 1.7; 95\% CI: 1.02.9). The breeds "Taurin" (multiple OR: 0.8; 95\% CI:
0.3-2.5) and "Zébu" (multiple OR: 0.6; 95\% CI: 0.3-1.0) had lower odds of infection compared to the "Taurin $x$ Zébu”, but the difference lacked statistical significance.

\section{Spatial distribution of Schistosoma and Fasciola infection in livestock}

The prevalence of schistosomiasis and fascioliasis varied by department and host species, with the highest prevalence observed in the northern part of Côte d'Ivoire (Fig. 1). As shown in Table 1, the highest prevalence of schistosomiasis in cattle sampled in slaughterhouses was found in Ouangolodougou (53.3\%, 95\% CI: 37.9-68.3\%), while the highest prevalence of fascioliasis was observed in Katiola (40.6\%, 95\% CI: 23.7-59.4\%). The lowest prevalence of schistosomiasis in slaughtered cattle was observed in Duekoué (5.9\%, 95\% CI: 0.7-19.7\%). Fascioliasis was absent in slaughtered cattle in Niakaramadougou and Toumodi.

In farm cattle, F. gigantica was considerably more prevalent than S. bovis (Fig. 3b). As summarized in Table 3, the highest prevalence of F. gigantica in farm cattle was observed in Dikodougou (50.8\%), whilst the highest prevalence of $S$. bovis was found in Ouangolodougou (2.4\%).

In slaughtered sheep, Schistosoma spp. infection was present in Ferkessédougou and Sikensi with respective prevalences of $7.1 \%$ (95\% CI: $0.2-33.9 \%$ ) and $7.7 \%$ (95\% CI: $0.2-36.0 \%)$. Slaughtered goats were also found infected with Schistosoma spp. in Ferkessédougou (6.9\%; 95\% CI: 0.0-9.7\%). In Korhogo, sheep were infected with F. gigantica (2.8\%; 95\% CI: $0.1-14.5 \%)$, but not with Schistosoma and goats were not infected with either parasite. In slaughtered goats and sheep, the highest prevalence of Fasciola infection was recorded in sheep in Duekoué (8.0\%; 95\% CI: 1.0-26.0\%). On farms, Schistosoma spp. were detected in sheep in Sinématiali $(1.1 \%$; 95\% CI: $0.0-6.0 \%)$ and goats in Ferkessédougou (13.6\%; 95\% CI: 2.9-34.9\%) (Table 3). Fascioliasis was found in farm sheep with a prevalence of $8.3 \%$ (95\% CI: $2.8-$ 18.4\%) and 12.2\% (95\% CI: 6.3-20.8\%) in Ferkessédougou and Sinématiali, respectively (Table 3 ).

\section{Discussion}

The prevalence and distribution of trematodes belonging to the genera Schistosoma and Fasciola in slaughtered and live livestock were assessed in the savannah (Centre and North) and forest (South and West) areas of Côte d'Ivoire. The results showed that schistosomiasis and fascioliasis are endemic in Côte d'Ivoire. Schistosoma and Fasciola infection were found at all the investigated sites. Cattle were infected more often with Schistosoma spp. and $F$. gigantica than goats and sheep, both in slaughterhouses and on farms. Sex was not associated with parasitic infections in slaughtered animals. However, 


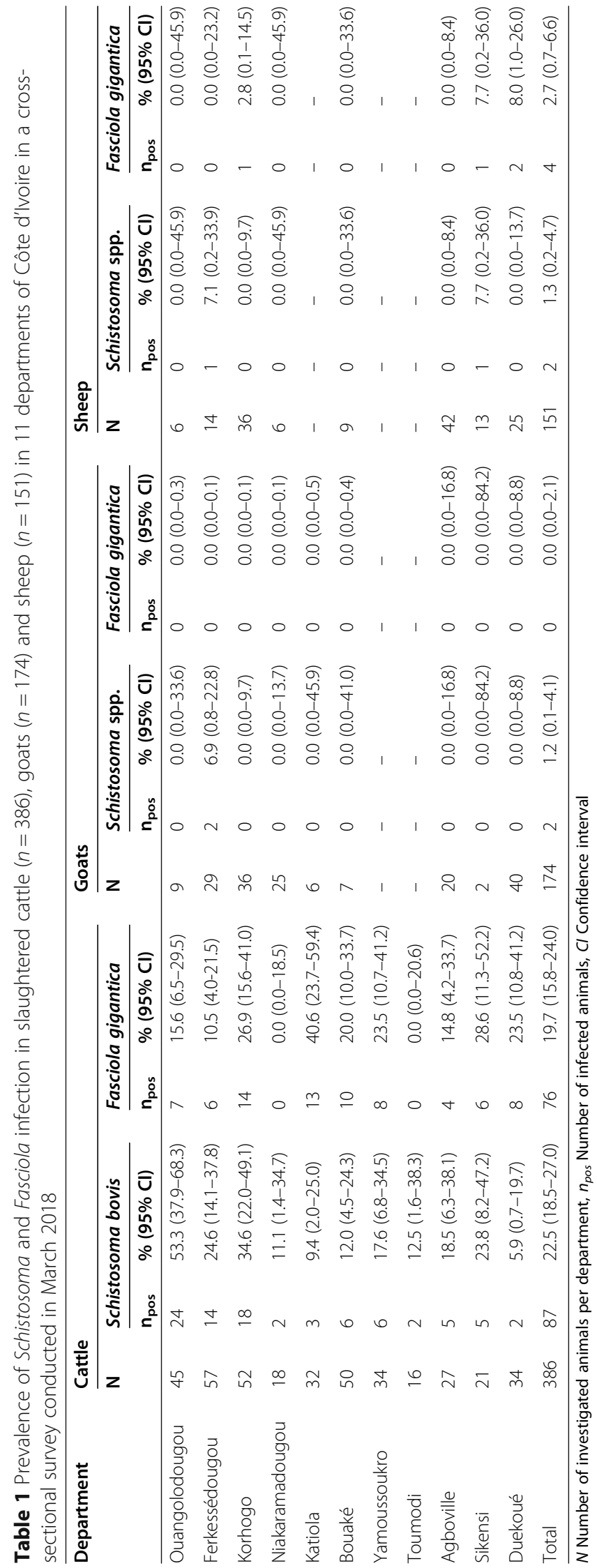


Table 2 Multiple logistic GEE model analysis of variables associated with Schistosoma bovis and Fasciola gigantica infection among slaughtered cattle, adjusted for potential correlation within slaughterhouse in a cross-sectional survey conducted in Côte d'Ivoire in March 2018. Note that 82 animals from Agboville, Sikensi and Duekoué were not included in the analysis because of missing data on age

\begin{tabular}{|c|c|c|c|c|c|c|c|}
\hline \multirow[t]{2}{*}{ Trait } & \multirow[t]{2}{*}{$\mathrm{N}$} & \multicolumn{3}{|c|}{ Schistosoma bovis } & \multicolumn{3}{|c|}{ Fasciola gigantica } \\
\hline & & $\begin{array}{l}\text { Infected } \\
\mathrm{n}_{\text {pos }}(\%)\end{array}$ & Multiple OR & $95 \% \mathrm{Cl}$ & $\begin{array}{l}\text { Infected } \\
\mathrm{n}_{\text {pos }}(\%)\end{array}$ & Multiple OR & $95 \% \mathrm{Cl}$ \\
\hline \multicolumn{8}{|l|}{ Sex } \\
\hline Female & 192 & $49(25.5)$ & & & $37(19.3)$ & & \\
\hline Male & 112 & $26(23.2)$ & 1.1 & $0.6-1.8$ & $21(18.8)$ & 1.0 & $0.6-1.6$ \\
\hline \multicolumn{8}{|l|}{ Age (years) } \\
\hline $1-3$ & 62 & $9(14.5)$ & & & $7(11.3)$ & & \\
\hline$\geq 4$ & 242 & $66(27.3)$ & 2.4 & $1.0-5.6$ & $51(21.1)$ & 2.1 & $1.1-3.9$ \\
\hline \multicolumn{8}{|l|}{ Breed } \\
\hline Taurin $\times$ Zébu & 107 & $31(29.0)$ & & & $26(24.3)$ & & \\
\hline Taurin & 77 & $20(26.0)$ & 0.9 & $0.3-2.8$ & $8(10.4)$ & 0.4 & $0.2-0.9$ \\
\hline Zébu & 120 & $24(20.0)$ & 0.6 & $0.2-1.8$ & $24(20.0)$ & 0.7 & $0.5-1.1$ \\
\hline
\end{tabular}

$N$ Investigated animals, $n_{\text {pos }}$ Number of infected animals, $\mathrm{Cl}$ Confidence interval, OR Odds ratio

in farm cattle, males were infected more often with Schistosoma than females and the spatial distribution of infections showed that the highest prevalence was found in the northern part of the country.

The distribution of Schistosoma and Fasciola is governed by the presence of multipurpose dams and other freshwater bodies (e.g. rivers) and animal-water contact sites (for schistosomiasis) and consumption of aquatic plants (for fascioliasis). The river networks running North to South is of particular relevance, as it provides habitats for intermediate snail hosts. In addition, the livestock system itself may play an essential role in maintaining the transmission of schistosomiasis. In traditional livestock-systems, animals graze and drink water near and from rivers and dams, depositing faeces containing the parasite eggs, perpetuating the life cycle. A study carried out in the southern highlands of Tanzania demonstrated that livestock management systems influence the epidemiology of trematode infection. Indeed, it was found that the prevalence of trematodes was high in areas where traditional systems were practiced, moderate in large-scale dairy systems and lowest in small-scale dairy systems [44]. In Mali, another study showed that factors such as climatic conditions, presence of rivers and lakes, and livestock management practices influence the prevalence of trematode infections [38].

The prevalence of schistosomiasis and fascioliasis in goats and sheep was low compared to cattle. Cattle graze away from the villages and consume water from rivers and dams. Goats and sheep, in contrast, often graze around the villages and consume water that is provided by farmers. This likely reduces the contact with infested freshwater and reduces the risk of Schistosoma infection in goats and sheep. Our findings are in line with a previous study in the south-eastern Lake Chad area that reported a higher prevalence of adult liver flukes in cattle than sheep and goats [45]. Frequent grazing of cattle near the lake emerged as the key risk factor. In Iran, another study also reported a lower prevalence of Fasciola in goats and sheep compared to cattle. This observation was explained by the fact that goats consume leaves and heaths in elevated areas, sheep graze on open land, while cattle pasture near the springs and streams, and hence, cattle are at a higher risk of exposure to snail-infested freshwater [46].

The two trematode infections appear to be more prevalent in Côte d'Ivoire than elsewhere in sub-Saharan Africa. Indeed, the prevalence of $53.3 \%$ of Schistosoma is more than 2-fold higher than that recorded in South Ghana (21.7\%) [19]. The prevalence of Fasciola (50.8\%) in the current study is higher than previously recorded in the northern part of Côte d'Ivoire (4\%) [23]. Our prevalence estimate is also higher compared to research conducted in Ethiopia (31.3\%) [47]. However, other studies also showed prevalences above $50 \%$; for instance in Chad (68\%) [45], Ghana (51.1\%) [19] and Zambia (53.9\%) [48]. These high rates in Côte d'Ivoire may be due to the extensive farming systems with little or no veterinary input. The lack of a control programme against trematodes leads to livestock owners medicating their animals with commonly used anthelminthic drugs such as albendazole and nitroxynil without a prescription from a veterinary. Triclabendazole [49], the drug of choice against Fasciola is not available for use in Côte d'Ivoire. Praziquantel, which is highly effective against all visceral bovine schistosomiasis [50], is also not commercially available for livestock in the country. These factors likely contribute to the endemicity of livestock schistosomiasis and fascioliasis. 


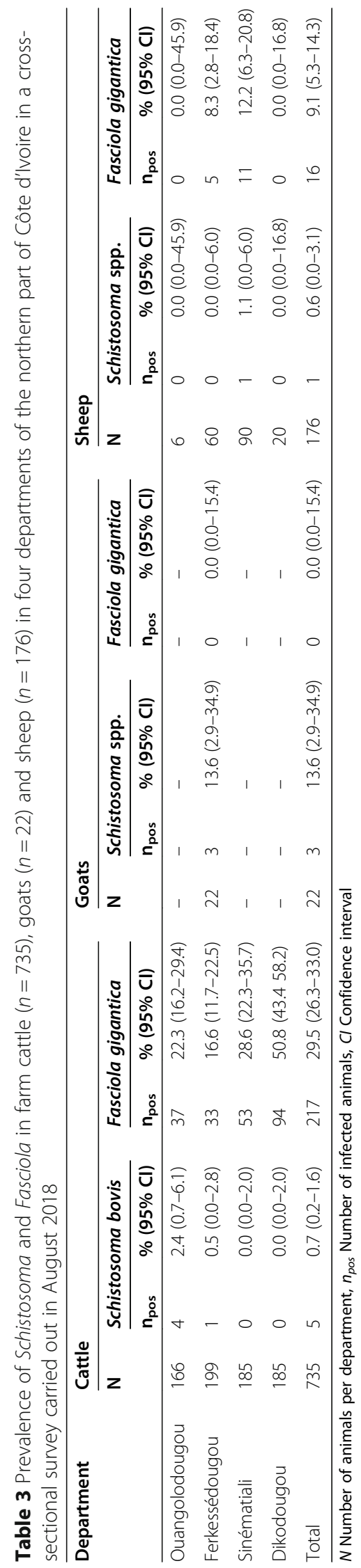


Table 4 Multiple logistic GEE model analysis of variables associated with Schistosoma bovis and Fasciola gigantica infection among farm cattle, adjusted for potential correlation within farms in a cross-sectional survey carried out in Côte d'Ivoire in August 2018

\begin{tabular}{|c|c|c|c|c|c|c|c|}
\hline \multirow[t]{2}{*}{ Trait } & \multirow[t]{2}{*}{$N$} & \multicolumn{3}{|c|}{ Schistosoma bovis } & \multicolumn{3}{|c|}{ Fasciola gigantica } \\
\hline & & $\begin{array}{l}\text { Infected } \\
\mathrm{n}_{\text {pos }}(\%)\end{array}$ & Multiple OR & $95 \% \mathrm{Cl}$ & $\begin{array}{l}\text { Infected } \\
\mathrm{n}_{\text {pos }}(\%)\end{array}$ & Multiple OR & $95 \% \mathrm{Cl}$ \\
\hline \multicolumn{8}{|l|}{$\overline{S e x}$} \\
\hline Female & 563 & $2(0.4)$ & & & $173(30.7)$ & & \\
\hline Male & 172 & $3(1.7)$ & 4.3 & $0.7-26.9$ & $44(25.6)$ & 1.1 & $0.8-1.7$ \\
\hline \multicolumn{8}{|l|}{ Age (years) } \\
\hline $1-3$ & 150 & $2(1.3)$ & & & $33(22.0)$ & & \\
\hline$\geq 4$ & 585 & $3(0.5)$ & 0.6 & $0.2-2.3$ & $184(31.5)$ & 1.7 & $1.0-2.9$ \\
\hline \multicolumn{8}{|l|}{ Breed } \\
\hline Taurin x Zébu & 587 & $4(0.7)$ & & & $183(31.2)$ & & \\
\hline Taurin & 37 & $0(0.0)$ & ND & ND & $10(27.0)$ & 0.8 & $0.3-2.5$ \\
\hline Zébu & 111 & $1(0.9)$ & ND & ND & $24(21.6)$ & 0.6 & $0.3-1.0$ \\
\hline
\end{tabular}

$N$ Investigated animals, $n_{\text {pos }}$ Number of infected animals, $C l$ Confidence interval, ND Not determined because of low number of infected individuals in several categories, OR Odds ratio

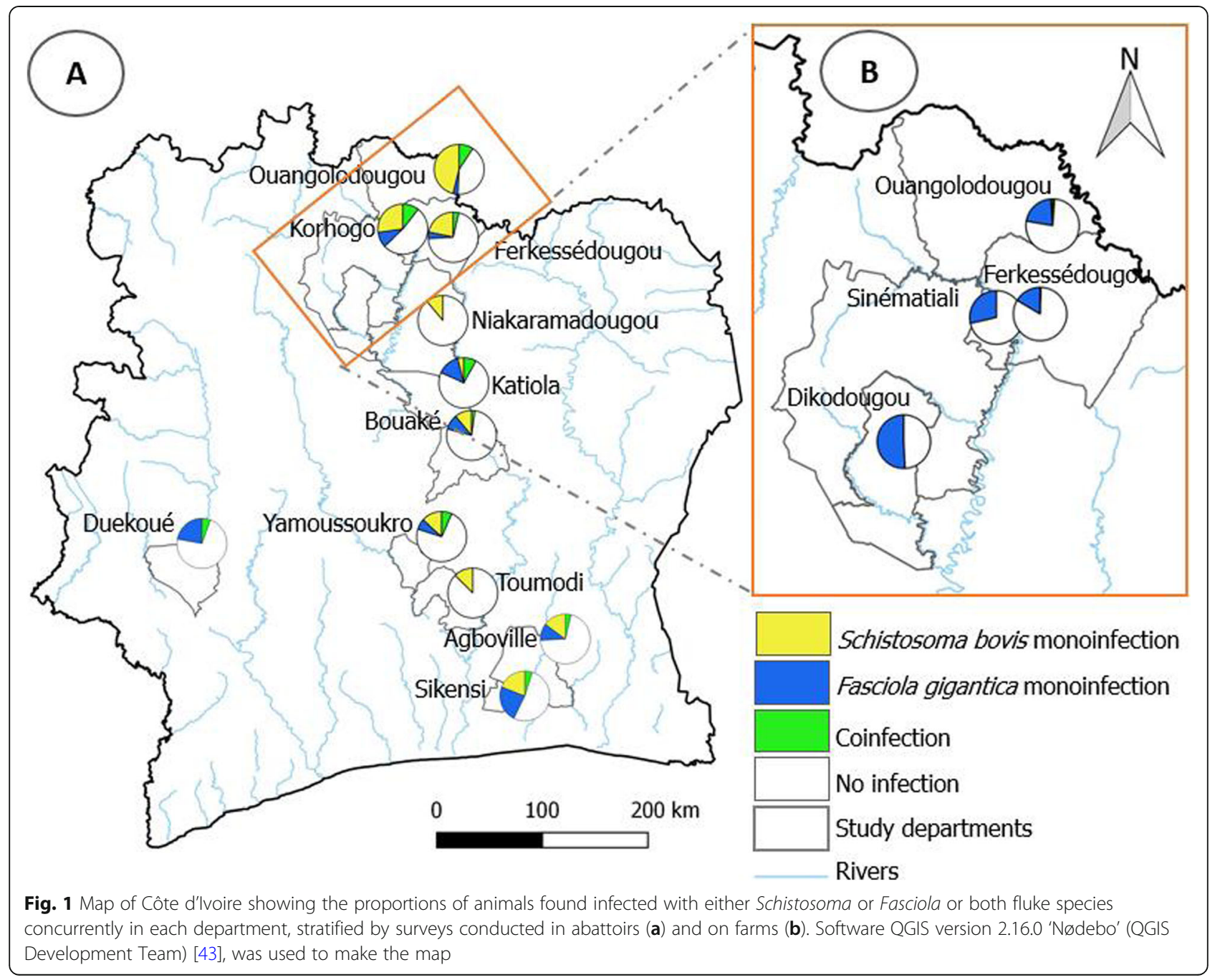


Schistosoma infection was particularly high in male cattle on farms. A prior study from Nigeria showed that the prevalence of Fasciola was higher in male cattle than in females [51]. In that study, the authors speculated that the high infection rate in male cattle could be attributed to the fact that the males were more often slaughtered for consumption, while the females were left for milk production and breeding. This may have led the herdsmen to ensure that the females graze on clean pasture and drink clean water [51].

In slaughtered animals, sex was not associated with Schistosoma and Fasciola infection. In contrast to the aforementioned Nigerian abattoir survey [51], the prevalence of Schistosoma and Fasciola infection in farm cattle was higher in males than in females. Results concerning this issue are thus not consistent, as there are studies that report higher prevalence in male cattle $[13,52]$ and others that report higher prevalence in females $[53,54]$.

Cattle aged 4 years and older were infected more often by $S$. bovis and F. gigantica than their younger counterparts in slaughterhouses. This finding might be explained by the fact that farmers predominantly butcher older animals or animals that are ill to avoid the death of the animal on the farm, which would result in economic losses. It is conceivable that older animals are in contact with contaminated water for longer periods than younger animals that are kept on the farm for breeding. This is in agreement with studies that reported similar findings in Nigeria [16, 18] and Tanzania [55, 56]. Others studies from western Ethiopia [47] and in the Philippines [57] showed a statistically significant association of the age of the cattle with the prevalence of fascioliasis. In addition, when the cattle get older, their immunity against Fasciola might decrease [58]. However, studies found a higher prevalence rate of fascioliasis in young cattle than in adults $[48,59]$ and rationalised that older animals would develop acquired immunity that resulted in resistance [60].

The higher prevalence of Schistosoma and Fasciola found in the northern parts of Côte d'Ivoire compared to the South might be explained by the many small multipurpose dams built in the North in the 1970s and 1980s. Indeed, dams play a crucial role in maintaining the lifecycle of snail-borne infections, and some studies have shown the presence of intermediate snail hosts of Schistosoma and Fasciola in North Côte d'Ivoire [61, 62]. In Senegal, trematode infection increased after the construction of large dams across major rivers in the Senegal River basin [63]. The northern part of Côte d'Ivoire is also home to the largest livestock production in the country. The lower prevalence found in the central, southern and western regions could mean that there is a lower parasite pressure on animals compared to the North. The lowest prevalence of schistosomiasis in slaughtered cattle was observed in Duekoué, the western forested area of the country. Studies in humans in Western Côte d'Ivoire showed that S. mansoni is the predominant species [20, 64]. Unlike in cattle, the highest prevalence of fascioliasis in small ruminants was observed in sheep in the forested areas. However, the sample size was not large enough to draw firm conclusions.

The prevalence of Schistosoma in cattle was lower on farms and higher in slaughterhouses, while the opposite was observed for Fasciola. These observations should be interpreted with caution because the two populations of cattle differ in important ways, and the animals tested were not from the exact same places. Therefore, results from farms could not be compared to those from abattoirs.

The following considerations are offered for discussion. First, farm populations are more diverse in regards to age and include calves and young cattle that have had little time to be infected. Second, the cattle at slaughterhouses may be ill, their illness being the reason that they are brought for slaughter. Third, the prevalence of bovine schistosomiasis is often higher in wet season compared to the dry season [16]. As the farm sampling in this study was carried out in the rainy season in the North (August 2018), we expected the prevalence of schistosomiasis to be higher as seen in other investigations $[65,66]$. Yet the prevalence was low there and the high prevalence of schistosomiasis was found in dry season (March 2018) in the abattoirs. In regards to the low schistosomiasis prevalences, sedimentation technique has been shown to have a low sensitivity, depending on the protocol. This may be due to factors that affect coprology in general, such as variation in the distribution of eggs within a single faeces specimen; daily fluctuations of faecal production and consistency in the host; and daily fluctuations related to oviposition patterns of the parasite [67-69]. The sensitivity is also influenced by the time samples are left to sediment. This is due to the rapid hatching of Schistosoma eggs, which may occur during the sedimentation process before the sediment is observed on the slide [70]. In fact, after exposure to water, Schistosoma eggs can hatch within $20 \mathrm{~min}$ [71]. In this study, the total time eggs were left to sediment in water was $45 \mathrm{~min}$. It may also be because not all Schistosoma eggs are excreted in the faeces, many are left trapped the in tissue [52]. Lastly, the immune reaction of host organisms against schistosomes is not primarily directed towards the elimination of adult worms but rather towards the suppression of worm fecundity [72], also leading to reduced egg output. However, with post-mortem examination, adult flukes can be easily detected in the mesenteric vein or liver.

The higher prevalence of Fasciola observed in farm cattle might be due to the higher endemicity of Fasciola in the breeding areas. In addition, faecal examination appears to be more sensitive for Fasciola egg detection. 
Corroborating this finding, a study in South Ethiopia found a higher prevalence of Fasciola in farm cattle [73]. The higher prevalence of fascioliasis in this study could be due to the fact that sampling was done during the rainy season in the northern part of Côte d'Ivoire. In fact, fascioliasis prevalence is known to vary depending on the season, with an increase in prevalence during the wet season [41, 74, 75]. In contrast, an abattoir study in Southwestern Nigeria reported a higher prevalence of fascioliasis in the dry season compared to the rainy season [76]. To investigate further the epidemiology of trematode infections in livestock in Côte d'Ivoire, a seasonal study of both infections is needed.

Our study has some limitations. First, we did not count the eggs of parasites in the faeces of farm animals; we only determined the prevalence but not the intensity of infection. Second, the sample sizes at some abattoirs were small especially for goats and sheep; in addition, farms from central, southern and western parts of Côte d'Ivoire were less sampled than farms in the North, as livestock populations are mainly concentrated in the northern parts of Côte d'Ivoire. Third, we did not record the history of the treatments that might influence the prevalence of trematodes on farms. However, this study highlights the importance of veterinary trematodes in Côte d'Ivoire, as well as provides prevalence information for regions not previously sampled and updates the existing literature on livestock schistosomiasis and fascioliasis in West Africa, particularly in Côte d'Ivoire.

\section{Conclusions}

Animal schistosomiasis and fascioliasis are prevalent in abattoirs and on farms across Côte d'Ivoire, with the highest prevalence found in the North. Our study revealed that Fasciola and Schistosoma infection are both associated with older age cattle and male sex. In view of our findings, a strategic control programme for cattle trematodes is warranted. An important component of such a control programme is to water cattle in troughs rather than to let them freely consume water from ponds, in order to reduce faecal contamination.

\section{Methods}

\section{Study area}

The study was conducted in 13 departments located in the northern, central, southern and western parts of Côte d'Ivoire: Ouangolodougou, Ferkessédougou, Sinématiali, Korhogo, Dikodougou, Niakaramadougou, Katiola, Bouaké, Yamoussoukro, Toumodi, Agboville, Sikensi and Duekoué (Fig. 2). The areas in the North and the Centre are characterised by a tropical climate and savannah vegetation with some forested areas. The South and West are in the tropical rainforest zone. Rainfall is higher in the southern and western parts, compared to the central and northern parts.
The South and West also have less grass for livestock than the central and northern parts. The hydrography is composed of rivers running from North to South and several small multipurpose dams, mainly used for cattle breeding in the North [77]. The rivers and dams provide suitable habitats for intermediate host snails of schistosomiasis and fascioliasis [61] and the savannah with its grass is favourable for cattle breeding.

\section{Sampling and study design}

Two cross-sectional surveys were carried out in March and August of 2018 to determine the prevalence of schistosomiasis and fascioliasis in cattle, goats and sheep. The first survey was conducted to obtain an overview of the prevalence of schistosomiasis and fascioliasis in slaughtered animals, in 11 of the 13 departments across the full geographical range. At least 3 days were spent at each local abattoir, where the livers and small intestines from slaughtered livestock were excised during the routine meat inspection. The samples were stored and transferred to a nearby laboratory of the "Direction Départementale du Ministère des Ressources Animales et Halieutiques". There, livers and small intestines were examined for Fasciola and Schistosoma flukes. Demographic information such as sex, age, breed and origin were recorded. The animals in the abattoirs came from the local villages or in the northern part of the country, in particular for central, southern and western abattoirs. Of course, there were transhumant animals from the northern border countries, Mali and Burkina Faso, but these animals were not included in the study.

The second cross-sectional survey aimed to determine the prevalence of schistosomiasis and fascioliasis in farm animals and was restricted to the departments of Ouangolodougou, Ferkessédougou, Sinématiali and Dikodougou. These sites were chosen due to the high prevalences of infection detected there in the first cross-section study, in combination with the presence of dams and water bodies frequented by both humans and animals, in the area. A total of 16 farms (in villages) were randomly selected, four farms from each department. Rectal sampling was conducted under license as mentioned in the ethics approval and consent to participate section. After consent from the farmers, veterinary technicians collected faecal samples from the rectums of cattle, goats and sheep, as well as demographic information for each animal. Both abattoir and farm samplings were carried out in the dry season (March) and rainy season (August), respectively. The average monthly temperature and precipitation for the study months sampled are shown in the supplemental material (Additional file 1).

The sample size was determined based on the expected prevalence $(p)$ of bovine fascioliasis and the desired absolute precision $(d)$ and $95 \%$ confidence interval $(\mathrm{CI})$ by 


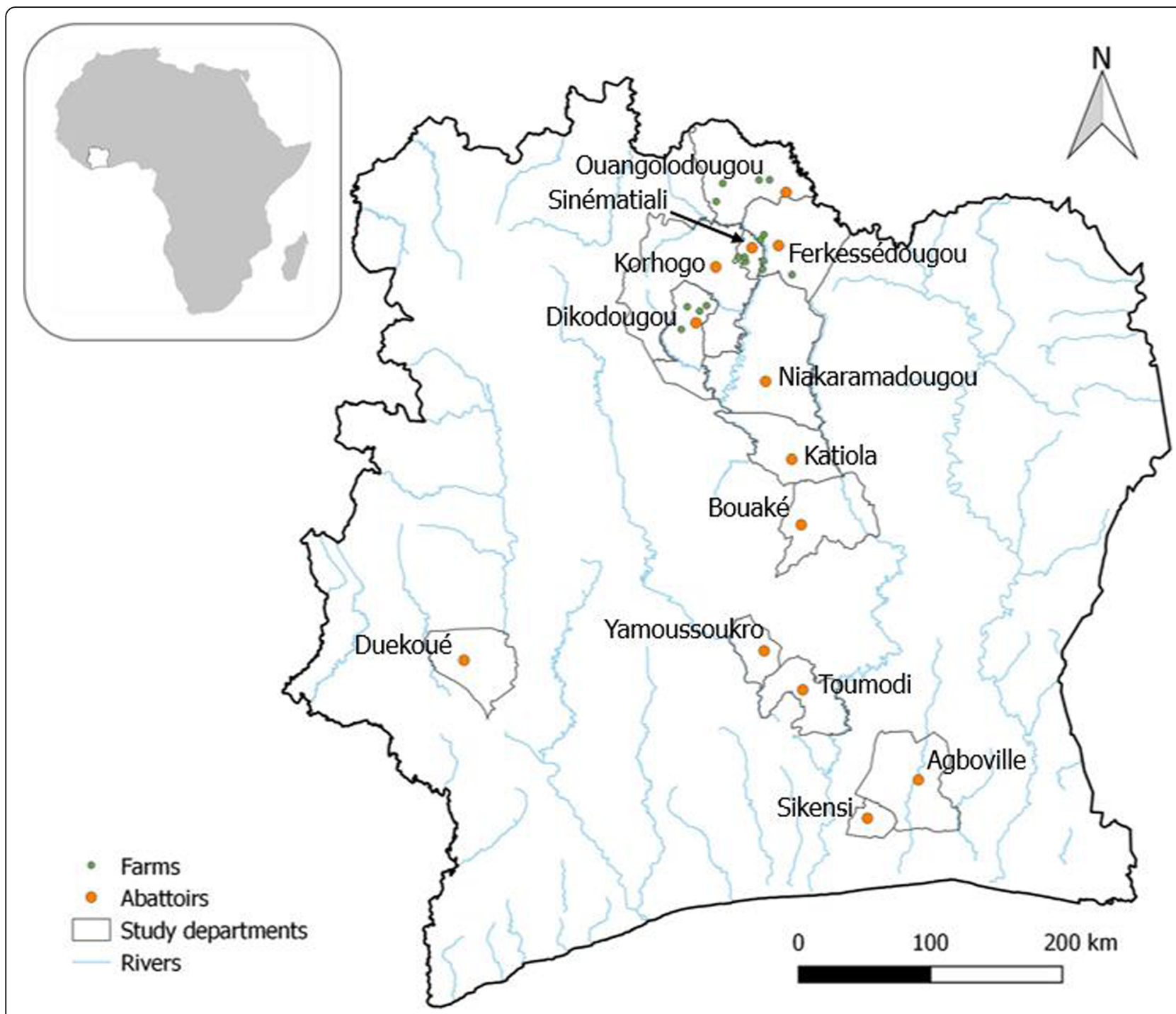

Fig. 2 Map of Côte d'Ivoire highlighting the 13 departments where sampling for fascioliasis and schistosomiasis was conducted. Livestock from 11 abattoirs and 16 farms were sampled during two cross-sectional surveys in 2018. Software QGIS version 2.16.0 'Nødebo' (QGIS Development Team) [43], was used to make the map

using the formula $n=\left(\mathrm{Z}^{2} * p^{*}(1-p)\right) / d^{2}$, where $\mathrm{Z}=1.96$, $p=60 \%$ and $d=5 \%$ [78]. Thus, a sample size of 369 animals was ascertained for each group of animals, from either slaughterhouses or farms.

\section{Laboratory procedures}

Macroscopic inspection of the small intestine and liver of animals for adult flukes was carried out in the laboratory. The mesenteric veins of the small intestine (Fig. 3a) and hepatic veins were examined for schistosomes. Fasciola were recovered from the biliary duct and the parenchyma of the liver (Fig. 3b) [45].

Faecal samples from farm animals were processed by a sedimentation method [79]. In brief, approximately $5 \mathrm{~g}$ of faeces was placed in a cup and mixed with $30 \mathrm{ml}$ of tap water. The faecal suspension was sieved through a $400 \mu \mathrm{m}$ sieve into a $500 \mathrm{ml}$ conical beaker. Tap water was added until the beaker was almost full. The conical beaker sat undisturbed for $15 \mathrm{~min}$. The supernatant was decanted, and the sediment re-suspended in tap water. The process of suspension and decanting was repeated three times. Finally, using a pipette, a drop of the sediment was transferred onto a slide, stained with methylene blue (1\%) and examined under a microscope for parasite eggs.

\section{Statistical analysis}

Data were double entered into Epilnfo version 3.5.4 (Centers for Disease Control and Prevention; Atlanta, USA) and checked for internal consistency. R software version 3.5.2 [80] was used to calculate proportions and 


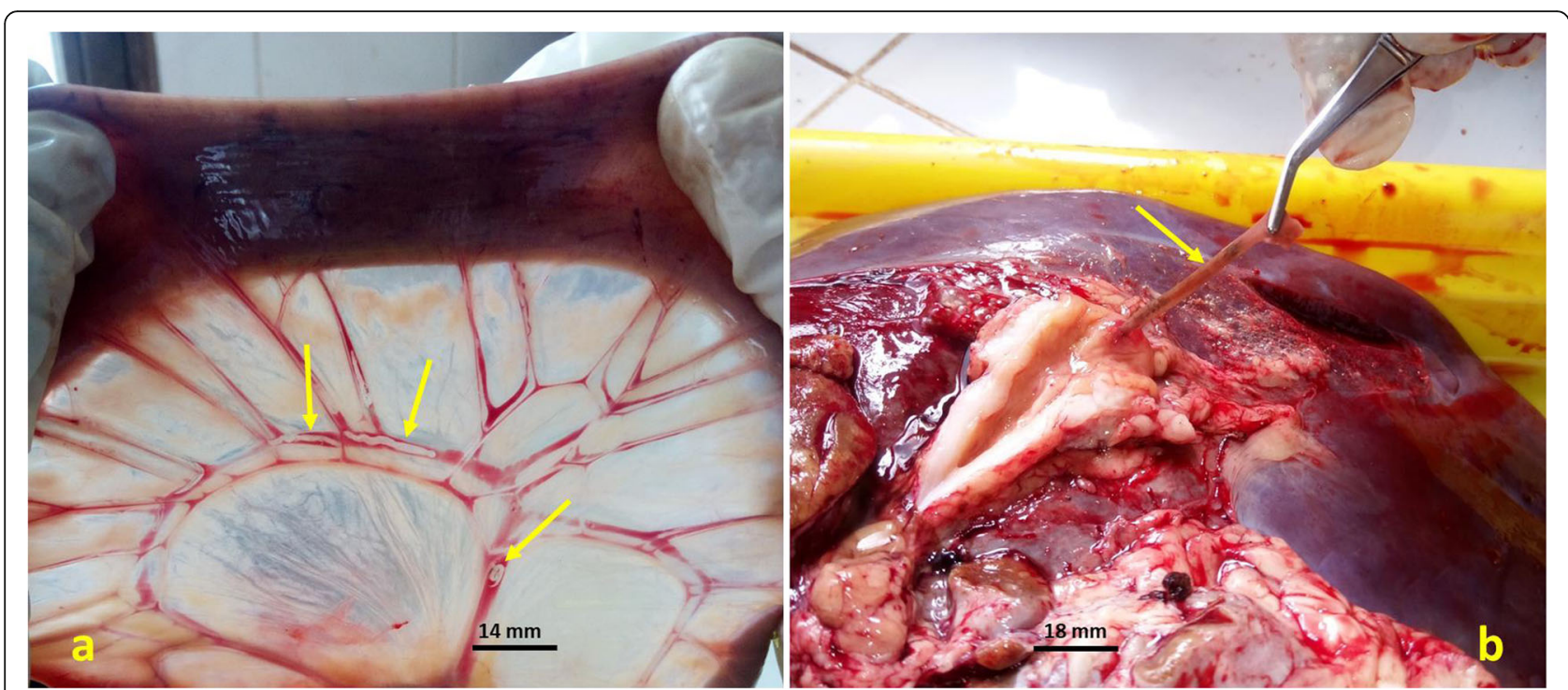

Fig. 3 Schistosoma flukes in mesenteric veins of the small intestine (a) and a Fasciola fluke in a cattle liver (b)

95\% CIs. Associations between parasitic infections and risk factors (sex, age and breed) were assessed using generalized estimating equation (GEE) analysis for binary outcomes with farms and slaughterhouses as clusters. Animals from Agboville, Sikensi and Duekoué were not included in the GEE analysis due to missing data on animal traits in these areas.

\section{Supplementary Information}

The online version contains supplementary material available at https://doi. org/10.1186/s12917-020-02667-y.

Additional file 1. Climate diagram of the northern (a), central (b), southern (c) and western (d) areas of Côte d'Ivoire in 2018.

\section{Abbreviations}

Cl: Confidence interval; OR: Odds ratio; S: Schistosoma; F: Fasciola;

$p$ : Prevalence; $d$ : Desired absolute precision; GEE: Generalized estimating equation

\section{Acknowledgements}

We would like to thank the employees of the "Ministère des Ressourses Animales et Halieutiques de Côte d'Ivoire" for their assistance in the field, as well as the "Laboratoire National d'Appui au Devéloppement Agricole (LANADA) for the use of their laboratories in central and northern parts of Côte d'Ivoire. We are deeply grateful to the farmers for providing access to their livestock. We thank Dr. Etienne K. Angora for his contribution to the improvement of the manuscript.

\section{Authors' contributions}

JNK, JGE, LYA, DF, MO, KDS, BB, JH, JU, JZ, OB and EKN conceived of and designed the study. JNK, JGE, LYA and DF conducted the study. JNK and JH analysed and interpreted the data. JNK wrote the first draft. JGE, LYA, DF, $\mathrm{MO}, \mathrm{KDS}, \mathrm{BB}, \mathrm{JU}, \mathrm{JZ}, \mathrm{OB}$ and EKN revised the manuscript. All authors read and approved the final version of the manuscript.

\section{Funding}

This work was financially supported by the Swiss National Science Foundation (grant no 31003A_170113). The funder had no role in study design, data collection, analysis and interpretation, or preparation of the manuscript.

\section{Availability of data and materials}

The datasets used and/or analysed during the current study are available from Dr. Oliver Balmer on reasonable request.

\section{Ethics approval and consent to participate}

The study was a part of a project entitled "Transmission dynamics and hybridization of human and animal trematodes in Côte d'Ivoire" that was approved by the National Ethics Committees of Côte d'Ivoire (reference no.: 035/MSH /CNER-kp) and Switzerland (UBE-2016-00707). In addition, the "Direction des Services Vétérinaires" of the "Ministère des Ressources Animales et Halieutiques de Côte d'Ivoire" authorized the study. The farmers signed informed consent forms for the sampling of their animals. International and national guidelines for the care and use of animals were followed.

\section{Consent for publication}

Not applicable.

\section{Competing interests}

The authors declare that they have no competing interests.

\section{Author details}

${ }^{1}$ Unité de Formation et de Recherche Biosciences, Université Félix Houphouët-Boigny, 22 BP 770 Abidjan 22, Abidjan, Côte d'Ivoire. ${ }^{2}$ Centre Suisse de Recherches Scientifiques en Côte d'Ivoire, 01 BP 1303 Abidjan 01, Abidjan, Côte d'Ivoire. ${ }^{3}$ Swiss Tropical and Public Health Institute, P.O. Box CH-4002 Basel, Switzerland. ${ }^{4}$ University of Basel, P.O. Box CH-4001 Basel, Switzerland. ${ }^{5}$ Ecole de Spécialisation en Elevage et des Métiers de la Viande de Bingerville, BP 58 Bingerville, Abidjan, Côte d'Ivoire. 'University of Zurich, Ramistrasse 71, P.O. Box CH-8006 Zurich, Switzerland.

Received: 12 March 2020 Accepted: 4 November 2020

Published online: 17 November 2020

\section{References}

1. Angeles JMM, Leonardo LR, Goto Y, Kirinoki M, Villacorte EA, Hakimi H, et al. Water buffalo as sentinel animals for schistosomiasis surveillance. Bull World Health Organ. 2015;93:511-2.

2. Mas-Coma S, Valero MA, Bargues MD. Climate change effects on trematodiases, with emphasis on zoonotic fascioliasis and schistosomiasis. Vet Parasitol. 2009;163:264-80.

3. Mas-Coma S, Bargues MD, Valero MA. Human fascioliasis infection sources, their diversity, incidence factors, analytical methods and prevention measures. Parasitology. 2018;145:1665-99. 
4. McManus DP, Dunne DW, Sacko M, Utzinger J, Vennervald BJ, Zhou X-N. Schistosomiasis. Nat Rev Dis Primer. 2018;4:13.

5. Lai Y-S, Biedermann P, Ekpo UF, Garba A, Mathieu E, Midzi N, et al. Spatial distribution of schistosomiasis and treatment needs in subSaharan Africa: a systematic review and geostatistical analysis. Lancet Infect Dis. 2015;15:927-40.

6. GBD 2017 DALYS and HALE Collaborators. Global, regional, and national disability-adjusted life-years (DALYs) for 359 diseases and injuries and healthy life expectancy (HALE) for 195 countries and territories, 1990-2017: a systematic analysis for the Global Burden of Disease Study 2017. Lancet Lond Engl. 2018;392:1859-922.

7. Saleha AA. Liver fluke disease (fascioliasis): epidemiology, economic impact and public health significance. Southeast Asian J Trop Med Public Health. 1991;22(Suppl):361-4.

8. You H, Cai P, Tebeje B, Li Y, McManus D. Schistosome vaccines for domestic animals. Trop Med Infect Dis. 2018;3:68.

9. Yusuf M, Ibrahim N, Tafese W, Deneke Y. Prevalence of bovine fasciolosis in municipal abattoir of Haramaya, Ethiopia. Food Sci Qual Manag. 2016:48:38-43.

10. Catalano S, Sène M, Diouf ND, Fall CB, Borlase A, Léger E, et al. Rodents as natural hosts of zoonotic Schistosoma species and hybrids: an epidemiological and evolutionary perspective from West Africa. J Infect Dis. 2018;218:429-33.

11. Modena CM, Lima W d S, Coelho PMZ. Wild and domesticated animals as reservoirs of Schistosoma mansoni in Brazil. Acta Trop. 2008:108:242-4.

12. Standley CI, Dobson AP, Stothard JR. Out of animals and back again: schistosomiasis as a zoonosis in Africa. In: Schistosomiasis. InTech; 2012. p. 209-30.

13. Yihunie A, Urga B, Alebie G. Prevalence and risk factors of bovine schistosomiasis in northwestern Ethiopia. BMC Vet Res. 2019;15:12.

14. Boissier J, Grech-Angelini S, Webster BL, Allienne J-F, Huyse T, Mas-Coma S, et al. Outbreak of urogenital schistosomiasis in Corsica (France): an epidemiological case study. Lancet Infect Dis. 2016;16:971-9.

15. Webster BL, Diaw OT, Seye MM, Webster JP, Rollinson D. Introgressive hybridization of Schistosoma haematobium group species in Senegal: species barrier break down between ruminant and human schistosomes. PLoS Negl Trop Dis. 2013;7:e2110.

16. Elelu N, Eisler MC. A review of bovine fasciolosis and other trematode infections in Nigeria. J Helminthol. 2018:92:128-41.

17. Rollinson D, Southgate VR, Vercruysse J, Moore PJ. Observations on natural and experimental interactions between Schistosoma bovis and S. curassoni from West Africa. Acta Trop. 1990;47:101-14.

18. Elelu N, Ambali A, Coles GC, Eisler MC. Cross-sectional study of Fasciola gigantica and other trematode infections of cattle in Edu local government area, Kwara state, north-Central Nigeria. Parasit Vectors. 2016;9:470.

19. Squire AS, Amafu-Dey H, Amafu-Dey J. Epidemiology of gastrointestinal parasites of cattle from selected locations in southern Ghana. Livest Res Rural Dev. 2013;25:13.

20. Angora EK, Boissier J, Menan H, Rey O, Tuo K, Touré AO, et al. Prevalence and risk factors for schistosomiasis among schoolchildren in two settings of Côte d'Ivoire. Trop Med Infect Dis. 2019;4:110.

21. Assaré RK, Tian-Bi Y-NT, Yao PK, N'Guessan NA, Ouattara M, Yapi A, et al. Sustaining control of Schistosoma mansoni in western Côte d'Ivoire: results from a SCORE study, one year after initial praziquantel administration. PLoS Negl Trop Dis. 2016;10:e0004329.

22. Chammartin F, Houngbedji CA, Hürlimann E, Yapi RB, Silué KD, Soro G, et al. Bayesian risk mapping and model-based estimation of Schistosoma haematobium-Schistosoma mansoni co-distribution in Côte d'Ivoire. PLoS Negl Trop Dis. 2014;8:e3407.

23. Achi YL, Zinsstag J, Yéo N, Dea V, Dorchies PH. Les nématodes gastrointestinaux des bovins de la région des savanes de la Côte d'Ivoire: enquête d'abattoir. Rev Médecine Vét. 2003;154:105-14.

24. Angora EK, Allienne J-F, Rey O, Menan H, Touré AO, Coulibaly JT, et al. High prevalence of Schistosoma haematobium $\times$ Schistosoma bovis hybrids in schoolchildren in Côte d'lvoire. Parasitology. 2019;147:287-94.

25. Tian-Bi Y-NT, Webster B, Konan CK, Allan F, Diakité NR, Ouattara M, et al. Molecular characterization and distribution of Schistosoma cercariae collected from naturally infected bulinid snails in northern and central Côte d'Ivoire. Parasit Vectors. 2019;12:117

26. Beesley NJ, Caminade C, Charlier J, Flynn RJ, Hodgkinson JE, MartinezMoreno A, et al. Fasciola and fasciolosis in ruminants in Europe: identifying research needs. Transbound Emerg Dis. 2018;65:199-216.
27. Bennema SC, Molento MB, Scholte RG, Carvalho OS, Pritsch I. Modelling the spatial distribution of Fasciola hepatica in bovines using decision tree, logistic regression and GIS query approaches for Brazil. Parasitology. 2017;144:1677-85.

28. Greter H, Batil AA, Ngandolo BN, Alfaroukh IO, Moto DD, Hattendorf J, et al. Human and livestock trematode infections in a mobile pastoralist setting at Lake Chad: added value of a one health approach beyond zoonotic diseases research. Trans R Soc Trop Med Hyg. 2017;111:278-84.

29. Malatji MP, Pfukenyi DM, Mukaratirwa S. Fasciola species and their vertebrate and snail intermediate hosts in east and southern Africa: a review. J Helminthol. 2019;94(e63):1-11.

30. Parkinson M, O'Neill SM, Dalton JP. Endemic human fasciolosis in the Bolivian Altiplano. Epidemiol Infect. 2007;135:669.

31. Ichikawa-Seki M, Peng M, Hayashi K, Shoriki T, Mohanta UK, Shibahara T, et al. Nuclear and mitochondrial DNA analysis reveals that hybridization between Fasciola hepatica and Fasciola gigantica occurred in China. Parasitology. 2017;144:206-13.

32. Peng $M$, Ichinomiya $M$, Ohtori $M$, Ichikawa M, Shibahara T, Itagaki T. Molecular characterization of Fasciola hepatica, Fasciola gigantica, and aspermic Fasciola sp. in China based on nuclear and mitochondrial DNA. Parasitol Res. 2009;105:809-15.

33. Wannasan A, Khositharattanakool P, Chaiwong P, Piangjai S, Uparanukraw P, Morakote N. Identification of Fasciola species based on mitochondrial and nuclear DNA reveals the co-existence of intermediate Fasciola and Fasciola gigantica in Thailand. Exp Parasitol. 2014;146:64-70.

34. Giovanoli Evack J, Schmidt RS, Boltryk SD, Voss TS, Batil AA, Ngandolo BN, et al. Molecular confirmation of a Fasciola gigantica $\times$ Fasciola hepatica hybrid in a Chadian bovine. J Parasitol. 2020:106:316.

35. Addy F, Romig T, Wassermann M. Genetic characterisation of Fasciola gigantica from Ghana. Vet Parasitol Reg Stud Rep. 2018;14:106-10.

36. Periago MV, Valero MA, Panova M, Mas-Coma S. Phenotypic comparison of allopatric populations of Fasciola hepatica and Fasciola gigantica from European and African bovines using a computer image analysis system (CIAS). Parasitol Res. 2006;99:368-78.

37. Assogba MN, Youssao AKl. Prévalence de la fasciolose bovine à Fasciola gigantica (Cobbold, 1885) dans les principaux abattoirs du Bénin. Rev Méd Vét. 2001;152:699-704.

38. Tembely S, Galvin TJ, Craig TM, Traore S. Liver fluke infections of cattle in Mali. An abattoir survey on prevalence and geographic distribution. Trop Anim Health Prod. 1988;20:117-21.

39. Adediran OA, Adebiyi Al, Uwalaka EC. Prevalence of Fasciola species in ruminants under extensive management system in Ibadan southwestern Nigeria. Afr J Med Med Sci. 2014;43(Suppl):137-41.

40. Shinggu PA, Olufemi OT, Nwuku JA, Baba-Onoja EBT, lyawa PD. Liver flukes egg infection and associated risk factors in white Fulani cattle slaughtered in Wukari, southern Taraba State, Nigeria. Adv Prev Med. 2019;2019:2671620.

41. Dada EO, Jegede SO. Prevalence of fascioliasis and dicrocoeliasis in cattle slaughtered in some abattoirs in Akure Metropolis, Ondo State, Nigeria. Int J Pathog Res. 2019;3:1-7.

42. Magaji AA, Ibrahim K, Salihu MD, Saulawa MA, Mohammed AA, Musawa Al. Prevalence of fascioliasis in cattle slaughtered in Sokoto metropolitan abattoir, Sokoto, Nigeria. Adv Epidemiol. 2014;2014:1-5.

43. Projecta: Entries -. https://changelog.qgis.org/en/qgis/version/2.16.0/. Accessed 11 Jun 2020

44. Keyyu JD, Monrad J, Kyvsgaard NC, Kassuku AA. Epidemiology of Fasciola gigantica and amphistomes in cattle on traditional, small-scale dairy and large-scale dairy farms in the southern highlands of Tanzania. Trop Anim Health Prod. 2005:37:303-14.

45. Jean-Richard V, Crump L, Abicho AA, Naré NB, Greter H, Hattendorf J, et al. Prevalence of Fasciola gigantica infection in slaughtered animals in SouthEastern Lake Chad area in relation to husbandry practices and seasonal water levels. BMC Vet Res. 2014;10:81.

46. Kordshooli MS, Solhjoo K, Armand B, Dowlatkhah H, Jahromi ME. A reducing trend of fasciolosis in slaughtered animals based on abattoir data in south of Iran. Vet World. 2016;10:418-23.

47. Tulu D, Gebeyehu S. Study of prevalence and associated risk factors of bovine fasciolosis in Jimma Horro district of Kellem Wollega zone. Arch Vet Sci Med. 2018;1:009-18.

48. Phiri AM, Phiri IK, Sikasunge CS, Monrad J. Prevalence of fasciolosis in Zambian cattle observed at selected abattoirs with emphasis on age, sex and origin. J Vet Med Ser B. 2005;52:414-6. 
49. Keiser J, Engels D, Büscher G, Utzinger J. Triclabendazole for the treatment of fascioliasis and paragonimiasis. Expert Opin Investig Drugs. 2005;14:1513-26.

50. De Bont J, Vercruysse J. The epidemiology and control of cattle schistosomiasis. Parasitol Today. 1997;13:255-62.

51. Odigie BE, Odigie JO. Fascioliasis in cattle: a survey of abattoirs in Egor, Ikpoba-Okha and Oredo local government areas of Edo state, using histochemical techniques. Int J Basic Appl Innov Res. 2013;2:1-9.

52. Melkamu S. Study on prevalence and associated risk factors of bovine and human schistosomiasis in Bahir Dar and its surrounding areas. J Anim Res. 2016;6:967-75

53. Chanie M, Dejen B, Fentahun T. Prevalence of cattle schistosomiasis and associated risk factors in fogera cattle, South Gondar zone, Amhara National Regional State, Ethiopia. J Adv Vet Res. 2012;2:153-6.

54. Setargew M, Fentahun T, Chanie M. Prevalence of bovine shistosomiasis in Fogera district, South Gondar zone, Amhara National Regional State, Northwest Ethiopia. Glob Vet. 2012;9:612-6.

55. Nzalawahe J, Kassuku AA, Stothard JR, Coles GC, Eisler MC. Associations between trematode infections in cattle and freshwater snails in highland and lowland areas of Iringa Rural District, Tanzania. Parasitology. 2015;142:1430-9.

56. Nzalawahe J, Kassuku AA, Stothard JR, Coles GC, Eisler MC. Trematode infections in cattle in Arumeru District, Tanzania are associated with irrigation. Parasit Vectors. 2014;7:107.

57. Portugaliza HP, Balaso IMC, Descallar JCB, Lañada EB. Prevalence, risk factors, and spatial distribution of Fasciola in carabao and intermediate host in Baybay, Leyte, Philippines. Vet Parasitol Reg Stud Rep. 2019;15:100261.

58. Zewde A, Bayu Y, Wondimu A. Prevalence of bovine fasciolosis and its economic loss due to liver condemnation at Wolaita Sodo municipal abattoir, Ethiopia. Vet Med Int. 2019;2019:9572373.

59. Yatswako S, Alhaji NB. Survey of bovine fasciolosis burdens in trade cattle slaughtered at abattoirs in north-Central Nigeria: the associated predisposing factors and economic implication. Parasite Epidemiol Control. 2017;2:30-9.

60. Mungube EO, Bauni SM, Tenhagen BA, Wamae LW, Nginyi JM, Mugambi $\mathrm{JM}$. The prevalence and economic significance of Fasciola gigantica and Stilesia hepatica in slaughtered animals in the semi-arid coastal Kenya. Trop Anim Health Prod. 2006:38:475-83.

61. Krauth SJ, Wandel N, Traoré SI, Vounatsou P, Hattendorf J, Achi LY, et al. Distribution of intermediate host snails of schistosomiasis and fascioliasis in relation to environmental factors during the dry season in the Tchologo region, Côte d'Ivoire. Adv Water Resour. 2017;108:386-96.

62. Cecchi P, Baldé S, Yapi YG. Mollusques hôtes intermédiaires de bilharzioses dans les petits barrages. In: L'eau en partage, les petits barrages de Côte d'Ivoire. Paris, France: IRD Editions; 2007. p. 175-89.

63. Diaw OT, Vassiliades $G$, Thiongane $Y$, Seye $M$, Sarr $Y$, Diouf A. Extension des trématodoses du bétail après la construction des barrages dans le bassin du fleuve Sénégal. Rev D'élevage Médecine Vét Pays Trop. 1998;51:113-20.

64. Yapi YG, Briët OJT, Diabate S, Vounatsou P, Akodo E, Tanner M, et al. Rice irrigation and schistosomiasis in savannah and forest areas of Côte d'Ivoire. Acta Trop. 2005;93:201-11.

65. Pfukenyi DM, Mukaratirwa S, Willingham AL, Monrad J. Epidemiological studies of Fasciola gigantica infections in cattle in the highveld and lowveld communal grazing areas of Zimbabwe. Onderstepoort J Vet Res. 2006:73:37-51.

66. Pfukenyi DM, Monrad J, Mukaratirwa S. Epidemiology and control of trematode infections in cattle in Zimbabwe: a review. J S Afr Vet Assoc. 2005;76:9-17.

67. Mas-Coma S, Bargues MD, Valero MA. Diagnosis of human fascioliasis by stool and blood techniques: update for the present global scenario. Parasitology. 2014;141:1918-46.

68. Valero MA, Panova M, Pérez-Crespo I, Khoubbane M, Mas-Coma S Correlation between egg-shedding and uterus development in Fasciola hepatica human and animal isolates: applied implications. Vet Parasitol. 2011;183:79-86.

69. Valero MA, Panova M, Comes AM, Fons R, Mas-Coma S. Patterns in size and shedding of Fasciola hepatica eggs by naturally and experimentally infected murid rodents. J Parasitol. 2002;88:308-13.

70. Giovanoli Evack J, Kouadio JN, Achi L, Balmer O, Hattendorf J, Bonfoh B, et al. Accuracy of the sedimentation and filtration methods for the diagnosis of schistosomiasis in cattle. Parasitol Res. 2020;119:1707-12.
71. Jones MK, Bong SH, Green KM, Holmes P, Duke M, Loukas A, et al. Correlative and dynamic imaging of the hatching biology of Schistosoma japonicum from eggs prepared by high pressure freezing. PLoS Negl Trop Dis. 2008;2:e334.

72. Lawrence JA. Schistosoma mattheei in sheep: the host-parasite relationship. Res Vet Sci. 1974;17:263-4

73. Chakiso B, Menkir S, Desta M. On farm study of bovine fasciolosis in Lemo district and its economic loss due to liver condemnation at Hossana municipal abattoir, southern Ethiopia. Int J Curr Microbiol Appl Sci. 2014;3: 1122-32.

74. Isah UM. Studies on the prevalence of fascioliasis among ruminant animals in northern Bauchi state, North-Eastern Nigeria. Parasite Epidemiol Control. 2019;5:e00090.

75. Gboeloh LB. Seasonal prevalence of Fasciola gigantica in slaughtered cattle in major abattoirs in Port Harcourt. Adv Agric Sci Eng Res. 2012;2:336-40.

76. Oladele-Bukola MO, Odetokun IA. Prevalence of bovine fasciolosis at the Ibadan municipal abattoir, Nigeria. Afr J Food Agric Nutr Dev. 2014;14:9055-77.

77. Cecchi P, Gourdin F, Koné S, Corbin D, Etienne J, Casenave A. Les petits barrages du nord de la Côte d'Ivoire : inventaire et potentialités hydrologiques. Sécheresse. 2009;20:112-22.

78. Thrusfield M. Veterinary epidemiology. Fourth edition. John Wiley \& Sons; 2018

79. Sirois M. Principles and practice of veterinary technology, 4th edition. 4th edition. St. Louis, Missouri. USA: Elsevier; 2017.

80. R Core Team. R: A language and environment for statistical computing. Vienna, Austria: R Foundation for Statistical Computing; 2019

\section{Publisher's Note}

Springer Nature remains neutral with regard to jurisdictional claims in published maps and institutional affiliations.

\section{Ready to submit your research? Choose BMC and benefit from:}

- fast, convenient online submission

- thorough peer review by experienced researchers in your field

- rapid publication on acceptance

- support for research data, including large and complex data types

- gold Open Access which fosters wider collaboration and increased citations

- maximum visibility for your research: over $100 \mathrm{M}$ website views per year

At $\mathrm{BMC}$, research is always in progress.

Learn more biomedcentral.com/submissions 